FedUni ResearchOnline

http://researchonline.federation.edu.au

This is a Submitted Manuscript of an article published by Taylor \& Francis in Gender and Education on 06/10/2015, available online: 


\section{'Power, regulation and physically active identities': The experiences of rural and regional living adolescent girls}

Casey, $\mathrm{M}^{1}$, Mooney, $\mathrm{A}^{2}$, Smyth, $\mathrm{J}^{3}$ and Payne, $\mathrm{W}^{4}$

${ }^{1}$ Federation University Australia, Faculty of Health, School of Health Sciences and Psychology.

${ }^{2}$ Deakin University, School of Education, Faculty of Arts and Education.

${ }^{3}$ School of Education and Professional Development University of Huddersfield, UK \& Emeritus Professor, Federation University Australia.

${ }^{4}$ Victoria University, Institute of Sport, Exercise and Active Living (ISEAL).

Corresponding author: Meghan Casey, Federation University Australia, School of Health Sciences and Psychology, PO Box 663, Ballarat, Victoria, 3353. Email: m.casey@federation.edu.au 


\begin{abstract}
Drawing on interpretations of Foucault's techniques of power, we explored the discourses and power relations operative between groups of girls that appeared to influence their participation in Physical Education (PE) and outside of school in sport and physical activity (PA) in rural and regional communities. Interviews and focus groups were conducted in eight secondary schools with Year $9(n=22)$ and 10 girls $(n=116)$. Dominant gendered and performance discourses were active in shaping girls' construction of what it means to be active or 'sporty', and these identity positions were normalised and valued. The perceived and real threat of their peer's gaze as a form of surveillance acted to further perpetuate the power of performance discourses; whereby girls measured and (self) regulated their participation. Community settings were normalised as being exclusively for skilled performers and girls self-regulated their non-participation according to judgements made about their own physical abilities. These findings raise questions about the ways in which power relations, as forged in broader sociocultural and institutional discourse-power relations, can infiltrate the level of the PE classroom to regulate and normalise practices in relation to theirs, and others, PA participation.
\end{abstract}

Keywords: gender, physical education, sport, physical activity, power relations, techniques of power, Foucault 


\section{Introduction}

Educational settings such as school PE and sport are important sites in shaping youth identities, wellbeing and promoting physically active lifestyles, yet extensive research exists to highlight how dominant and normalised practices around gendered bodies and physical abilities can be counterproductive to these espoused ideals (Azzarito and Solmon 2006a; Paechter 2003; Mooney, Casey, and Smyth 2012). Pressure to conform to particular versions of dominant gendered bodies is reported across both males and females, and young people generally (Atkinson and Kehler 2012; Garrett 2004). Researchers have highlighted sport and PE as an area where much positive 'body work' can be done yet despite this potential, there is growing evidence of the ways in which systemic power relations of cultural institutions, such as the school, are implicated in the normalisation and regulation of young people's bodies (Evans et al. 2008; Fitzpatrick 2013). Perhaps what is less well reported are the ways that rural and regional living adolescent girls negotiate these complex and multidirectional workings of power and discourse within the context of school PE to regulate their own, and impact upon others', PA participation. For as Cairn's $(2014,480)$ argues, ‘young people negotiate their meaning in the context of specific geographic and social locations ... they must negotiate the discourses available to them in order to establish their membership within legitimate categories of being'.

In drawing on recent work on the so-called 'obesity epidemic', Wright and Harwood (2009) present the concept of 'biopedagogies' to explore how individuals and populations are governed and regulated through practices associated with the body (drawing on Foucault's concept of bio-power) across various 'pedagogical' sites. As others have argued these 'pedagogical' sites are not limited to schools, pedagogy 'pervades every aspect of life (e.g. media websites, television, family, playgrounds...as well as school classrooms)' (Evans et al. 2008, 388). As such, each of these sites 'have the power to teach, to engage 'learners' in meaning making practices that they use to make sense of their worlds and their selves and thereby influence how they act on themselves and others' (Wright 2009, 7). We have argued that dominant institutional and cultural discourses relating to 
gender, performance and healthism were heavily implicated in the ways that rural and regional living adolescent girls constructed notions of their own physically active identities (Mooney, Casey, and Smyth 2012). As an extension to this previous work, and building on work that has examined the construction and regulation of gendered identities within the PE context (Azzarito and Solmon 2009; Flintoff and Scraton 2006; Paechter 2003; Wright 2001), this paper examines what adolescent girls' 'do' in terms of enacting, and often (re)producing, normalised bodies in the rural and regional PE context. Although cognisant of Wright's $(2009,2)$ assertions that through a 'biopedagogical' lens, 'individuals are being offered a number of ways to understand themselves, change themselves and take action to change others and their environments', we contend that an analysis of 'how' this occurs at the microlevel of the classroom is important. Specifically, we draw on interpretations of Foucault's techniques of power (for example see Gore 1998 and Wright, 2000) as a helpful lens to consider the nuanced effect of 'what' and 'how' messages about the body (and being physically active) are normalised and regulated amongst rural and regional living adolescent girls in the context of peer relations as enacted in school-based PE and sport.

\section{Girls' bodies, sport and physical education - Rurality and physical culture}

Various research findings have discussed the dominance of competitive team sports in the PE curriculum for their role in privileging particular gendered identities over others (Flintoff and Scraton 2006; Singleton 2006). Garrett (2004) explored the construction of a physical identity within the context of PE and PA and found that girls were strongly impacted by narrow conceptions of 'ideal' bodies. Others have highlighted the ways discourses act to privilege certain 'bodies' and promote a desire to express particular versions of 'femininity' ${ }^{1}$ amongst adolescent girls (Cockburn and Clarke 2002). For other girls who do not conform to dominant gendered identity positions, peer teasing and bullying is commonly reported (Bauer, Yang, and Austin 2004; Casey et al. 2009).

Slater and Tuggermann (2010) sought to gain a deeper understanding of the reasons that adolescent girls cease their participation in sports and physical activities. They found that girls (1315yrs) perceived that sport was 'uncool' and could harm their popularity; particularly during the 
transition from primary to secondary school when girls were increasingly concerned about their image and 'fitting in'. Gaining social acceptance and support such as developing friendships, gaining peer group acceptance, and having support from significant adults and peers has an important role in an adolescents' motivation to participate in sport and PA. Considering the centrality and visibility of the body in PE and sport contexts, it is not surprising that some adolescent girls choose to avoid participation for fear of being socially condemned or judged (Cockburn and Clarke 2002). Another way to further consider the ways in which the cultural practices of adolescent girls may be implicated in their participation (or lack thereof) in PE, sport and other PA settings is to explore the ways in which power relations appear to shape cultural practices. Few contributions have explored the interrelationships between geographical and social locations (e.g. rural sport or PE context) and the meanings young people make about their bodies and the various ways in which physically active identities can be taken up (or not). As others have argued, in addition to the 'type' of activity (such as sport, exercise or leisure activities) the physical culture of a particular context becomes integral if considered as the collective 'social practices involved with maintaining, representing, and regulating the body’ (Lee, Macdonald, and Wright 2009, 60).

Based on our previous work with adolescent girls in rural and regional contexts, we became attuned to the workings of particular discourses for the roles they played in shaping heteronormative and gendered subjectivities (Mooney, Casey, and Smyth 2012). For the adolescent girls involved in our research, and as reported in other research with Swedish adolescents (Larsson, Redelius, and Fagrell 2011), rural-living adolescent girls in Canada (Cairns 2014) and Australian rural males (Lee, Macdonald, and Wright 2009), 'normal' bodies and ways of being physically active are often judged and regulated against dominant identity positions. For adolescent girls, 'normal' is often judged when their appearance is feminine, they have good motor skill coordination and confidence in 'feminine' activities and lack self-confidence in aggressive and competitive games (Larsson, Redelius, and Fagrell 2011). Coll et al. (2014) contend that heterosexuality is typically espoused in PE classrooms where sports often operate as heteronormalized masculine or feminine activities, and ways of being during these activities that align with dominant gendered and sexual identity positions become the 
norm. For youth who display alternative identity positions, they are often targets of violence, bullying and homophobic slurs (Denison and Kitchen 2015) and are therefore forced to act more feminine (for girls) or more masculine (for boys) (Coll et al, 2014), to avoid certain identity labels which, for girls, might include "butch”, "manly”, "weak” or "emotional”. Of interest here however, are the ways in which certain subjectivities become normalised and regulated in the context of rural and regional PE and sport contexts. Put another way, how is 'normal' judged and how are various techniques of power (re)produced or resisted in the regulation of 'normal' by adolescent girls in rural and regional physically active contexts?

\section{Techniques of power and Biopedagogies: Regulating girls' bodies}

Foucault $(1977,1980)$ is well known for his critical studies of social institutions and his writings on power, knowledge and discourse. In Foucault's theorising, power is conceptualised as the web of power relations that individuals live in from day to day and he sought to recognise social factors that interact with power to reveal the effects these relationships can have in, on, and through institutional, cultural and social practices (Webb and Macdonald 2007). His work questions how certain bodies of knowledge, embodied subjectivities and socio-cultural practices come to be valued and privileged, and in which contexts. His theory of power recognises that power can be multi-directional, a site of resistance and mobilising action, and it acknowledges power as not always negative but also as both repressive and productive (Foucault 1988).

Foucault's thinking around power has been applied to understand dominant practices in PE and sport settings (Gore 1998, 1990; Wright 1995, 1996) and there is growing interest in such approaches more recently (Webb and Macdonald 2007; Webb, McCaughtry, and MacDonald 2004; Wright 2000; Mooney, Casey, and Smyth 2012). Gore (1998) considered how power relations function at the microlevel of pedagogical practices within her own PE Teacher Education (PETE) lessons and applied Foucault's $(1977,1980)$ concepts to outline eight techniques of power surveillance, normalisation, exclusion, classification, distribution, individualisation, totalization and regulation. Wright (2000) then drew on poststructuralist and linguistic theory and methodologies 
using Gore's (1998) interpretations to examine how the body is represented in texts derived from spoken language and explored the effect of that talk as it acts on bodies, to promote certain kinds of bodily behaviour and social relations. In doing so, Wright analysed PE lessons and identified how the organisation of these lessons lend themselves to the constant exercise of power, particularly on the part of the teacher who regulates what can be done, how it can be done, and where it can be done. The work of these educational researchers (Webb and Macdonald 2007; Webb, McCaughtry, and MacDonald 2004; Wright 2000; Gore 1998) examined the discursive effects of power that works in, on, and through institutions and cultural and social practices of PE; particularly in relation to how teachers regulate student behaviour in the classroom and the impact of power on PE teacher's careers and leadership.

More recently, Wright (2009) drew on Foucault's (1984) concept of biopower to discuss the escalating concerns over claims of the global 'obesity epidemic' and the impact of dominant obesity discourses on how children and young people come to know themselves. Wright argues that biopedagogical practices in education, as well as a range of social and institutional sites (e.g. government policy, health promotion initiatives and web resources) 'place individuals under constant surveillance' and 'encourage them towards increasingly monitoring themselves, often through increasing their knowledge around "obesity" related risks and instructing them on how to eat healthily, and stay active' (p.1). As a helpful construct, we wonder how similar 'surveillance' and 'monitoring' techniques influence PA participation for rural and regional living adolescent girls.

Elsewhere we have also drawn on the work of Foucault (Mooney, Casey, and Smyth 2012). We found that performance discourses that privileged physically skilled girls acted to marginalize and exclude those who did not display an acquired level of competence, and much of these exclusionary practices appeared to be self-regulated. We have also examined PE teachers and sports coaches' response to a school and community linked program to understand the ways in which PE teachers and sports coaches were positioned within the program and consider factors that shaped adolescent girls' experiences with, and response to the program (Mooney and Casey 2014). We found that there was 
evidence of performance discourses in which biophysical interests in skill, technique and fitness were privileged, particularly by sport coaches. We aim to extend this body of literature to further examine how techniques of power function to enhance understandings of the ways in which power is exercised, and experienced, by adolescent girls themselves and to consider how this impacts on their participation in rural and regional PA contexts.

\section{Methodology}

The methodology drew from ethnographic approaches and involved inviting girls from school PE classes to participate in semi-structured conversations about their PA involvement. As we previously reported (Casey et al. 2013) this approach was not to conduct ethnographies in the pure sense, but to employ ethnographic approaches to facilitate rapport with students, via observations and conversations with girls to allow a more in-depth understanding of the conditions surrounding how they made decisions about participating in PA. Our approach was also one of 'dialectical theory building' (Smyth 1998), whereby through the process of storytelling, girls told us about their lives and experiences as they related to PA. We then examined (a) the way in which existing theory around girls and PA helps to explain what girls told us about their lives and experiences as they related to PA and (b) how the girls' understandings of the way they made decisions about participation in PA, informed, confirmed, or caused us to refocus our initial theoretical presuppositions-and to that extent, this whole approach was a circular or reciprocal process of confirmation, refutation, or progressive readjustment (Casey et al. 2013).

This paper draws on qualitative interviews ( $\mathrm{n}=48$ ) and focus group discussions $(\mathrm{n}=25)$ with Year 9-10 female students (typically 15-16 years old) in eight secondary schools in rural and regional Victoria, Australia. The study was conducted between November 2009 and May 2010 to inform the development of a sport and recreation program that was offered both in secondary schools through PE curriculum and in the community. Ethical approval for this study was sought and obtained from the University Human Research Ethics Committee. Permission to conduct research in the schools was 
also sought and granted by the Victorian Department of Education and Early Childhood Development and the Victorian Catholic Education Office. Further, informed consent was provided from both parents and students.

Focus groups and interviews were semi-structured to explore the girls' experiences in PA at school- and outside of school. Specifically the prompts sought to understand the meanings that girls attached to their physical experiences and how these contributed to their participation in PA. Further, the prompts aimed to facilitate conversations about the things that made it easy or difficult for girls to participate in PE and community-based sport and PA settings. Each interview and focus group discussion was audio-taped and later transcribed, de-identified and labelled with a pseudonym.

\section{Participants}

Eight secondary schools from six communities were randomly selected and invited to participate on the basis of their socio-economic status of their community as defined by the Socio-Economic Indexes for Area (SEIFA) values assigned to their postcodes (Australian Bureau of Statistics 2008). The selection of communities and associated schools has been described in detail elsewhere (Smyth, Mooney, and Casey 2014; Mooney, Casey, and Smyth 2012). In short, the schools were located within low socioeconomic communities and these communities were considered 'highly accessible' (Accessibility and Remoteness Index of Australia: ARIA value less than 1.84) or 'accessible' (ARIA values between 1.85 - 3.51) indicating that there were some restrictions to accessibility of goods, services and opportunities for social interactions (Australian Institute of Health and Welfare 2004). The profile of the communities and school is summarised in Table 1. As highlighted in earlier reports of this study (Smyth, Mooney, and Casey 2014), whilst girls were drawn from schools located in communities considered 'disadvantaged', the interview process revealed that the socio-economic status of participants varied (subjectively identified by authors in terms of living arrangements, parental support, and parental unemployment). 
A total of 138 female students across the eight schools, aged 14-16 years and who were enrolled in Year $9(\mathrm{n}=22 ; 15.9 \%)$ or Year $10(\mathrm{n}=116$; 84.1\%) participated in the study. Researchers attended a PE class and invited girls to participate in interviews and focus groups discussions. Girls that accepted the invitation were organised into groups based on their PE teacher's subjective classification of their PA level: low $(n=44 ; 31.9 \%)$, medium $(n=51 ; 37.0 \%)$, or high $(n=43 ; 31.2 \%)$. The PE teacher's classifications were only used as a way to organise girls into focus groups that aimed to generate productive conversations with girls of apparent similar levels of interest in PA to discuss their own experiences and decisions around their participation. The classifications were not disclosed to students, but employed merely as a mechanism to organise groups for discussion (Mooney, Casey, and Smyth 2012). We acknowledge that the setting in which the interviews and focus groups occurred might have influenced how comfortable girls were discussing their experiences in PA. Further, girls may have made assumptions about the researchers' PA level as we were likely to be perceived as heteronormative, white, and middle class.

\section{Data Analysis}

As mentioned above, a poststructuralist perspective that drew on Gore's (1998) work of power relations in pedagogical practices, informed by Foucault's theorising of power $(1977,1980)$, was used to analyse the girls narratives. This approach was adopted to allow for an analysis of the taken-forgranted practices in PE and sport that shape our participants' subjectivities and to examine the ways in which these various subjectivities were implicated in regulatory and normalising practices in relation to PA participation. Law $(2004,2)$ argues, 'parts of the world are caught in our ethnographies, our histories and our statistics. But other parts are not ... If much of the world is vague, diffuse or unspecific, slippery, emotional, ephemeral, elusive or indistinct' then approaches to making sense of the girls' narratives needed to pay particular attention to the ways in which they described their practices in PA and the factors attributed to these practices. In analysing the participants' comments, we were also compelled to consider our own identity positions for the role they played in shaping 
'what' we saw in the data. Through our questioning of particular themes we became interested in the ways in which techniques of power appeared to normalise and regulate certain identity positions and ways of being physically active and these are discussed below.

\section{Findings}

Conversations with our participants about their participation in rural and regional PA settings appeared to be stories of the workings of power. Examples of seven, of the eight, techniques of power outlined by Gore (1998) were evident within the data and are discussed below including distribution, individualisation, totalisation, surveillance, classification, exclusion, normalisation. In this study, the collective influence of the evident power relations appeared to produce regulative, and perhaps even more obvious, self-regulative behaviours amongst the participants, particularly within the PE setting. As Webb and colleagues (Webb, McCaughtry, and MacDonald 2004, 209) state:

In terms of understanding how power functions in schooling, PE offers an important venue for study given the visual and active body. It is where the most flesh is seen, bodies interact constantly in different ways, and physicality is primary. Although power is embodied in all subject areas, the effects are magnified in PE where the context of study is both about and through the human body.

\section{'There is no 'I' in team': The netballers, the dancers and ...me}

Student: I'm still kind of friends with them, but not good friends.....you have got to be nice to them...

Interviewer: So those girls that you used to be friends with, are they particularly sporty people? What sort of things would they do?

Student: $\quad$ Not excessively. They play basketball and play netball. I don’t like them. I like swimming and stuff like that.

Interviewer: So what is it that you don't like about netball and basketball?

Student: I never really got into it...I can’t play because I always get obstructions. I don't really like it that much. And also the culture is 
different. It is footy/netball and I think, even at primary school, you are expected to know how to play because everyone plays, but you don't.

Interviewer: There are some girls that might be sporty girls and others that perhaps aren't? What does a sporty girl look like?

Student Well most of the time they are thinner, because they are fit. They don't necessarily have a certain look but if they are in that kind of clique, then they all kind of look the same, whether they do sport or not. Sport shorts, vollies, that is the general uniform.

(MPA, I, Seaside)

Individualisation is 'giving individual character to oneself or another' (Webb and Macdonald 2007, 282); and totalisation is 'the specification of collectives, giving collective character' (Gore 1998, 242) and in discourse analysis is often recognisable in the use of the word 'we' or when referring to whole groups (Webb and Macdonald 2007). Individualisation and totalisation are grouped together here as discussions with our participants often commenced with girls talking about the sport and leisure pursuits that they were engaged in, commenting on whether they were active or not, and comparing their PA levels to others.

The passage above highlighted the ways in which involvement in particular activities produced individualised or totalising (collective) identities. As one participant discussed above, particular activities have different 'cultures' in which some bodies (and identity positions) are privileged and others are not and key ways of being, including what you wear, became markers of this identity position. In particular, netball was generally considered a popular activity choice and girls often described their PA behaviour in relation to whether they played netball or not. Further, playing netball was often linked to being sporty and ideals of beauty - 'super active like the tall skinny girls' (MPA, I, Seaside) as well as being 'popular' often because of their strong social network that was developed through sport. Our participants reflected 'that's what everyone plays' (MPA, I, Seaside) 
and 'netball is just what you do in small towns if you are a girl' (MPA, I, St Luke's). Some girls were given the collective character 'the dancers' who 'look nice...wear make-up...and wear the nice shoes, not runners' (HPA, FG, Seaside). Other girls made comments that they were not as sporty or active mostly because they were self-conscious about their appearance or physical performance, which was often linked to peer acceptance within the PA, wider school and community environment. It was apparent that, in these rural and regional contexts, individual or totalising identity positions in relation to PA participation tended to regulate the types of activities girls participated in both within the school context and the wider community as discussed below. In both of these examples either peer or family support were identified as key drivers for participation.

I chose to do the circuit training because some of my friends are doing that and I wouldn't go and play basketball or netball because the people that play that, play that out of school so they know what they are doing and they have had a lot of practice, where I have no idea. (MPA, I, Seaside)

I'm not really a big sports person. I don't really enjoy team sports or anything but I do do some personal training with mum and stuff. We have a home gym. So we usually either get up early in the mornings or do it after dinner. (MPA, I, Seaside)

In analysing the ways in which individualised or totalising techniques of power acted to shape PA participation, it was interesting to note that when activities less common in the community context were undertaken in school PE, the power relations appeared somewhat diluted. For instance:

Student: $\quad$ Croquet and lawn bowls, that was fun...

Interviewer: What's different about those activities?

Student: It's still exercise, it's fun, it's sport, but it's not competitive. You might lose at bowling so clearly you are horrible, but no one says that, you just make a joke about it, everyone else is bad at it too.

Interviewer The sporty kids would they go on these activities and still be good at them?

Student: $\quad$ No they wouldn't. People in our class don't play croquet competitively. 


\section{'Everyone is watching and I am just not good enough': Power relations and perceptions of physical competence}

Surveillance of the female body, in terms of both physical performance and appearance was evident in our discussions with girls. Surveillance has been defined as 'supervising, closely observing, watching, threatening to watch, or expecting to be watched...surveillance singles out individuals, regulates behaviour, and enables comparisons to be made' (Gore 1998, 235-6). Surveillance can produce regulative effects on behaviour whereby individuals conform to established rules and norms if they know (or think) they are being watched. Surveillance, as a technology of power, dates back to Bentham's (1748-1832) theory of panoptical control which centred on the building of infrastructure to monitor prisoners in order to assist with their rehabilitation (Piro 2008). More recently, this theory has been applied to other institutions within society like schools as institutions of conformity (Piro 2008) and considered surveillance beyond architectural structures to surveillance of bodies and through behavioural practices (Webb, McCaughtry, and MacDonald 2004).

In this study our participants commonly described fears of being watched, especially by their peers during PE classes. They talked about 'everyone watching' and 'judging' their physical performance and especially feared taunts from their peers when they did not display an acquired level of competence. Unlike the theory of the panoptical control whereby surveillance was an attempt to reform behaviour, peer surveillance of PA behaviours was likely to create an environment that discouraged participation. For example, one group of girls who were described by their teachers as having low levels of PA, told us:

Student: If you are not as good as other people, if you are not as good they judge you, it puts you off.

Interviewer: How do they judge you?

Student: $\quad$ Like just judge you if you can’t do it. They yell out stuff.

Interviewer: So this concept of not being very good at a game, when did you make that decision? Is it just one experience that you have, then you are like, 'I am so not doing that again, because I was terrible' or is it 'oh, I threw the ball badly 
on that one occasion and it hit the wall but maybe I'll have another go'. Tell me what happens.

Student: $\quad$ You get embarrassed. It's not that you don’t want to do it. It's more like you don’t want to be humiliated really. You do it once badly and everyone makes fun of you and then you go to do it again, then they say oh she's going to do it again.

(LPA, FG, Westlands)

This discussion highlighted that girls were conscious of a 'critical' peer gaze and as a result of being watched and/or feelings of being watched, adolescent girls were quick to make judgements about themselves in terms of their physical performance. In this case, a negative appraisal about their physical performance was reported to impact on their confidence to make future attempts. It appears that unless adolescent girls perceived that they adequately met some predefined performance criteria they lacked confidence in their ability and often took measures to minimise their participation in particular physical activities, often to avoid unsolicited attention from their peers. In contrast, girls who were able to display competence and confidence in their own physical ability (often those selfidentified as sporty/active) not only reported predominantly positive experiences in this context, but actively sought opportunities in which to further challenge their abilities in competitive environments. For example, some girls reported they looked forward to participating with boys as they felt the boys provided greater competition (HPA, FG, Sunnyvale).

Girls also discussed wanting to 'look good' when being physically active and explained this using the PE setting as a point of reference 'you might want to do PE if you look good, you would feel more confident, running around getting all sweaty and looking weird...' (HPA, FG, Odessa). Further, they discussed anxieties about their appearance 'because chunky girls like me, in a pair of school shorts and a top, doesn't really match' (HPA, I, Rainbow). Some students even reported personal experiences or observations of other students being teased by their peers about their appearance. Feelings of surveillance were reported more frequently among girls who were described by their 
teachers as having medium and low levels of PA. These girls were more likely to comment that they lacked confidence in their skills and held deep anxieties about their self-image and appearance. In particular, participation in PE was often referred to as 'embarrassing' and 'humiliating' and as such was a potentially costly risk to their self-image and subsequent peer acceptance; especially in PE as 'it stands out more, if you do something wrong, or you don't win or you miss a goal or something...wear the wrong shorts...(they pick on you)' (LPA, FG, Southfield). In comparison, girls who were described as having high levels of PA by their teachers did not report feeling worried about their physical performance in PE; although some did have concerns about their appearance and not wanting to 'mess up their hair...they don't want to get dirty' (HPA, I, Seaside).

Girls’ perceptions of surveillance of the female body suggested the working of both dominant gendered and performance-related discourses, where an idealized feminine body (Azzarito 2009) and certain physical competencies are valued by the girls and their peers (Tinning 2010). In this study, there appeared to be a general idea about how one should perform in sport and PE contexts and girls adjusted their behaviour accordingly to perform/conform or decide that they cannot meet the norm and subsequently self-regulate their behaviour. In another contribution, we explored what these girls' considered as an ‘ideal’ performer (Mooney, Casey, and Smyth 2012). For many, ideal performers based their lives around sport, particularly club sport settings (e.g. 'Well some of the sporty girls, I don't know how to put it, their lives are very based around their sports... a lot of them are very selfobsessed with their netball', MPA, St Luke's). In these rural communities and small regional towns performance ideals were often reinforced in both the school and the community where girls who did not enjoy team sports discussed failing PE or for others the limited number of positions on a team meant that many did not make the squad:

sporty girls they are probably getting more of the praise because some of them are really good at sport and it builds up their self-esteem whereas other girls, the girls with not as many talents in sport . . . they probably don't feel as . . . important . . . especially in things like netball when there is only 9 girls per squad you get 20 girls trying out for the one squad . . . (HPA, I, St Luke’s) 
In problematizing the 'ideal', girls created a self-referencing frame that conformed to gendered aesthetics and interests to produce relatively monological performances of gender to reinforce what females are meant to be like. This has been reported by others (Butler 2004) whereby sport is framed as feminine or masculine - a concept that appeared to regulate if and how females participate (Roth and Basow 2004). Roth and Basow (2004, 252) discuss that the way in which sports are framed for females tend to emphasise 'not that women's bodies are capable of incredible strength, but that they are expected to demonstrate incredible femininity’ and associate female athleticism with female sex appeal. In our study, girls explained that 'some people just aren't confident with the way that they look playing sport...they think that are not good enough' (HPA, I, Westlands); whilst girls classified as having low levels of PA commented 'it's really hard to get into the sport' (LPA, FG, St Luke's). They explained that it was not necessarily a lack of interest that prevented their participation in sport; instead some girls excluded themselves because they perceived that their skill level was not adequate for the opportunities that were available. They reported that they wanted opportunities to participate with people who were at 'the same [skill] level' so that they did not feel 'like the one that sucks’ (LPA, I, Seaside). For example, one student explained:

I've thought about playing different sports but then you think, hang on a minute, I'm getting older now, there is so many people in this sport that have been playing for years. I can’t compete with them. (LPA FG, St Luke’s).

These findings allude to the complex and multi-directional relations of power, where the teacher, the home, the school and the community also influence the workings of power. It is within this web of discourse-power relations that girl's position themselves and often through the adoption of 'normalised' behaviours, appear to reproduce them. For instance, sport and PE in the community and school was often organised in a way that perpetuated performance discourses (Mooney and Casey 2014), the sporty/active girls who had already acquired the necessary skills to participate were normalised and validated in context on the basis of their physical competence. In addition, sporty/active girls were perceived to be privileged in the PA opportunities afforded to them; 
particularly in terms of access to resources in making decisions about their participation in PA such as familial resources (e.g. 'I don't have anyone [from home] to support me', LPA, I, Sunnyvale) and social connections (e.g. 'you have to know the right people or have a certain name to get into that [sports] club sometimes', MPA, I, St Luke's). Further, active girls were more likely to have a supportive PA network which encouraged them to be active (e.g. 'you just grow up with sport, it's a natural thing', HPA, I, Seaside). As we previously identified, 'the family and social class operate as key sites in the accumulation of cultural and social capital necessary to sustain PA' (Smyth, Mooney, and Casey 2014).

\section{'We all know what's normal for here... and its' just not us': Girls perceptions about normalised physically active identities}

Classification, exclusion, and normalisation are techniques of power with strong relationships with each other (Webb and Macdonald 2007) and therefore have been grouped and discussed together here. Normalisation refers to 'invoking, requiring, setting, or conforming to a standard - defining the normal' (Gore 1998, 237); whilst exclusion is often used to mark the negative side of normalisation (e.g. to define difference), and classification explains how differentiating groups or individuals classify them or oneself (Webb and Macdonald 2007).

In our conversations with girls they often classified themselves, and others, and made comparisons of their PA identities (e.g. sporty, competent, active, or not). For example, one girl proclaims 'I'm not sporty. I like sport but I'm not good at it. I can't be good at sport, I try and be good at sport but I can't do it' (LPA, I, Odessa); whilst a more competent and active peer from the same school accepts that the '[less competent or sporty girls] they think they can't do it, so they won't!' (HPA, I, Odessa). It appeared, girls classified and normalized their PA behaviour and everyone knew about it; particularly within the PE setting. For example, girls classified themselves and others into particular groups including - 'the plastics and the pops [popular individuals]'(LPA, FG, Henty), 'the sporty or netball girls' and 'the dancers' (HPA, FG, Seaside), the smokers or the 
westies (HPA, I, Rainbow High), and the yuks’ (LPA, FG, Sunnyvale High). What appeared evident in these ascribed classifications was not only an awareness of dominant discourses that shape 'gender performativity' (Butler 1990) but also a reproduction of them, particularly in the way that these act to limit participation through (self) exclusion and unproductive peer relations. Specifically, one girl described how her peers had used exclusion techniques in the school setting to limit access to social groups and how these girls then actively excluded girls during PE activities.

They will just talk about others and start rumours or whatever... they would be in a group and then suddenly they would all decide that they don't like one of the girls in the group, so they will ditch her and they just hide from her...(and in PE) they didn’t want to talk to these girls and didn’t want to throw the balls to these girls... (HPA, I, Seaside)

The active exclusion of girls during PE such as 'passing it (the ball) to the same people' resulted in girls feeling that they 'just want to stand back and be invisible' (LPA, FG, Seaside). Webb and Macdonald (2007) explain the ranking and classification of individuals and groups is common in schools. However, girls in this study reported that ranking and classification was amplified in PE settings because your appearance and physicality were often on display (e.g. 'I think bullying happens mostly during sport because you are doing stuff and you are showing your legs and whatever...' LPA, I, Rainbow). What was not explicit was the nature of the rumours, although, what was evident was that what happens within and around the school and community based on physical and social capacity was used by girls to position themselves and others in line with their social group classifications.

\section{Power, the body and hierarchical peer relations: Distribution in girls' physical education lessons}

Distribution is defined as 'the distribution of bodies in space - arranging, isolating, separating, ranking - contributes to the functioning of disciplinary power' (Gore 1998, 240) and often represents the spatial organization of individuals (Webb and Macdonald 2007). Two explicit examples of distribution as a technique of power were evident in the data and contributed to the (self)regulation of 
PA among girls. First, the classification and exclusion techniques outlined above resulted in students arranging, isolating, separating and ranking themselves and others into groups that functioned in the school setting. Within the school setting, girls who often had low levels of PA described groups functioning like a hierarchy, a food chain 'well the populars are up here, they're like the sharks and we're like the little fish... When you deal with them in other classes, if it is just them one on one, they're fine. They're perfect. They are nice people to talk to but when they all get together they are nasty' (MPA, FG, Henty). Consequently, this resulted in poor group dynamics and cohesion among some groups of girls who then went on to explain they hardly ever participated in PE because the 'people in it [PE] are crap...they put you down when you do it...everyone just bags you out for it' (LPA, FG, Southfield). In comparison, a group of girls described as having high levels of PA commented that they liked their class because 'everyone is friendly, and get along and don't like exclude people and all that, no-one gets put down in the class' (HPA, FG, Sunnyvale). These findings appear to be in conflict with existing literature that sport is 'uncool' and could harm a girl's popularity (Slater and Tiggemann 2010). Instead, girls who were perceived as sporty and demonstrated dominant performance and gendered PA discourses were often categorised as popular; whereas those who did not demonstrate dominant performance and gendered PA discourses were the ones who were 'uncool'.

The second way in which in distribution (as a technique of power) was evident was through the organisation of some PE classes as single-sex yet others as co-educational classes, and this was a contentious topic among girls. Comments from girls representative of sporty - non sporty, and active - non active, highlighted that boys can dominate and intimidate girls in the PE context as 'the boys are a bit rough, they take over, and they don't pass it to the girls' (HPA, FG, Sunnyvale). Whilst this was recognised by many students, the more active girls voiced their preference for co-educational classes because with single-sex classes 'I still don't think half the girls would participate. They just don't get into it. If they are not interested, they just don't try and can't be bothered' (HPA, FG, Seaside). Active girls also commented that they liked the competition with the boys, 'they make you push yourself more' (HPA, FG, Odessa) and 'its better with boys because there is not much conflict in 
the class, with girls, some people argue over things and people don't get along, but with guys they just want to play sport and everything is pretty good' (HPA, FG, Southfield).

\section{Implications and conclusions}

This paper aimed to explore the experiences of rural and regional living adolescent girls in PA contexts with a view to generating greater understandings about the factors that impacted on how they saw themselves as physically active beings, and specifically what they did with this knowledge. Through conversations with the girls about their involvement in PA (both within school PE and the broader community context) we were drawn to Foucault's notion of power as a lens through which to consider the ways in which our participants' negotiated power-discourse relations to regulate their own, and others, participation in PA. As an extension to previous work this study was particularly concerned with identifying techniques of power, predominantly between groups of girls, that (re)produced dominant discourses in ways that shaped physically active identities and experiences in PA contexts. In considering the implications of this work, we acknowledge that whilst care was taken to recruit participants to ensure a range of girls were represented in our conversations, there is a possibility that girls with an affinity for being physically active were more likely to become involved than others.

Although situated within rural and regional contexts, much of the discussions with our participants revealed themes consistent with previous research with adolescent girls in PA contexts. First, involvement in particular activities produced individualised or totalising (collective) identities, namely, that girls' PA behaviour was strongly impacted by narrow conceptions of 'ideal' bodies (Garrett 2004) and these were often linked to significantly limited meanings that they constructed about being physically active (Mooney, Casey, and Smyth 2012). Second, surveillance of the body was evident through dominant gendered and performance-related discourses, whereby girls were likely to feel 'judged' because of how they looked or felt that people were laughing at them because 
of their appearance or for being uncoordinated (Slater and Tiggemann 2011). Finally, examples of techniques of power relating to classification, exclusion, normalisation and distribution were apparent through the functioning of peer relationships and group dynamics. Inherent in many of the girls' conversations was a perception that there is a particular way of being in this context (physical ability, appearance, etc.,) that is privileged above other ways of being, and that girls were quite attuned to this, classifying and normalising their behaviours. Whilst we acknowledge that these presuppositions are likely forged from experiences both within and outside the PE context, we consider the concept of biopedagogies as helpful in exploring the number of ways that these rural and regional living adolescent girls understood themselves as physically active beings (or not), changed themselves (or not) and took action to change others and their environment (Wright, 2009).

In considering the intersections of rurality, place, power relations and identity we continually bumped into girls' perceptions about the ways in which participation in certain activities in these contexts became markers of physically active identities. For example, the centrality and importance of competitive team sports in the community, such as netball with the local football club and dancing, was often used as a default position from which to judge physical competence and to assign descriptors of their physically active identity. This finding is in contrast to other studies, which report that teenage girls perceive sport participation as ‘uncool' (Slater and Tiggemann 2010) and those who play masculine sports, or indeed sport at all, are likely to create for themselves a 'femininity deficit' and may be 'warned off physical activity' (Cockburn and Clarke 2002). Therefore, a femininity deficit is unlikely for feminine sports like netball or dance, compared to masculine sports like football.

The context of sport in regional Australia also requires some attention in the negotiation of physically active identities of adolescent girls as sport can play a significant role in the lives of rural and regional living Australians (Mooney, Casey, and Smyth 2012); particularly as sporting clubs are an important site for shaping collective and individual identities (Atherley 2006).

Not only is rural sport gendered (as is urban sport!), but the perceived centrality of football/netball clubs to the social and cultural fabric of rural communities in northwest 
Victoria can actually create social pressures to become involved in sporting activities....[and]

'visible minorities' are sometimes ostracized from social life in small towns because they do not become involved in sport activities (Spaaij 2009, 1143).

For rural and regional living adolescent girls sport can be a socially and culturally privileged activity, especially participation within local football-netball clubs and, as such, the dominance of these sports appear to significantly limit the meaning girls construct about being physically active (Mooney, Casey, and Smyth 2012). Football and netball are dominant sports throughout regional and metropolitan Australia, but there is often far greater choice of activities in metropolitan areas ${ }^{2}$. As such girls are able to select sports and physical activities that suit their preferences and level of competence (Craike et al. 2011) and may not experience the same challenges as their rural and regional counterparts.

Elsewhere we have argued that in rural and regional communities, the boundaries between cultural institutions becomes somewhat blurred as a result of small populations and limited resources to offer a wide variety of activities for PA participation (Mooney, Casey, and Smyth 2012). Specifically we pointed out that this acted to produce certain identity positions that became privileged across various PA contexts. For example, in comparison to metropolitan centres, 'local' sporting idols can occupy positions of privilege in both the community and sporting settings of rural communities and small regional centres as 'everyone knows you’ (Mooney, Casey, and Smyth 2012, 22). A relative few studies have examined socio-economic status, heteronormativity and space/place on PA participation and how power relations (re) produce or resist PA participation. Azzarito and Solmon (2006b, 90) found evidence that 'the dominant social discourses about the body, which are gendered and racialized, are institutionalised in schools and are relevant to students' normalizing processes and participation in physical education classes' among participants from rural and suburban areas of diverse economic and ethnic backgrounds. As an extension to this work, this paper has sought to consider 'what' and 'how' normalised messages about the body and being physically active 
are perpetuated in rural and regional contexts and manifest in peer-group power relations that act to regulate, both the actions of others and the self, in terms of PA participation.

Specifically, girls constructed individual and collective meaning about what it means to be active or sporty, which emphasised dominant gendered (feminine) and performance discourses, and that these identity positions were reproduced in the school-based PE context. Azzarito (2009, 36) argues 'physical education practices themselves are neither liberating nor oppressive. Rather, it is the individual's awareness of their agency in negotiating dominant discourses that make transformation possible'. This study highlighted, peer-group power relations influenced girls' (self) classification, particularly in terms of their gendered identity, physical ability and competence, and were key drivers that shaped and regulated school-based PA participation. Despite deliberate attempts to address concerns around a perceived focus on skill and physical performance and an attempt to reduce the amount of peer surveillance in PE lessons through the curricula program developed (Mooney and Casey 2014), opportunities and resources to assist girls in challenging and resisting these 'classifications’ requires a greater focus.

Performance discourses also appeared to be linked with social class as students with greater access to familial resources were perceived to be more privileged in terms of PA opportunities afforded to them outside of the school context; and as a result had greater opportunity to develop their performance skills. Similar to the findings of Garrett $(2004,233)$ active girls in this study were 'generally afforded opportunities to develop their physical skills outside of the school context and their experiences in physical education at school simply afforded them opportunities to display their physical competence'. For instance, the impact of socio-economic status (SES) on girls' participation was previously reported in Smyth, Mooney and Casey $(2014,11)$ where we discussed that:

"one of the proxies for class was often the extent to which parents in this regional town were able to convey the message to their progeny about the importance of PA, and to back that up materially by making themselves available to transport their children to venues in and out of school hours. Often this meant quite dramatically rescheduling things in their lives to make this a priority, and it was in marked 
contrast to poorer students who had no such 'sporty' role models and who were cared for by older siblings who were themselves overburdened with working to make ends meet often at multiple jobs”.

Educational researchers have identified systemic power relations within cultural institutions such as the school and HPE pedagogies (Wright and Burrows 2006). Wright and Burrows (2006) argued a need for ongoing discussions around 'physical ability' as the skills and competencies associated with organised sport continue to be privileged and embedded in social and cultural relations. A greater understanding of the social and institutional sites, and the broader geographical contexts in which they are situated that (re)produce dominant discourses is needed. Therefore, we should continue to question taken-for-granted identity positions and how HPE pedagogies and sport and PA policies and programs reaffirm feminine, performance, and social class discourses that encourage girls to self-regulate their participation in PA. In particular, we have largely undifferentiated between rural and regional contexts in this paper, and although distinct from metropolitan contexts there are likely to be significant differences between the voices from rural and regional settings. Future research should examine normalised identity positions in the context of specific geographical and social locations about how girls understand themselves and mediate their own understandings of self through a range of pedagogical sites (both locally within the community and nationally/globally through pedagogical sites such as the internet and television). Research should also aim to understand the role of the teacher, coach and/or instructor in body regulation such as minimising opportunities for surveillance, and developing positive relationships between girls with differing physically active identities will be important.

\section{Funding}

This work was supported by the Australian Research Council (ARC; LP0990206). Financial and/or in-kind support was also provided by industry partners, including the Victorian Health Promotion Foundation (VicHealth), Department of Health and Human Services-Sport and Recreation Victoria, 
Tennis Victoria, Football Federation Victoria, YMCA Victoria, Ballarat Aquatic Centre, and the Helen Macpherson Smith Trust.

\section{Acknowledgements}

The authors wish to thank secondary schools and their staff and students for their participation and contribution. We would also like to acknowledge the research team who were involved in the broader project - Dr Jack Harvey, Associate Professor Rochelle Eime, and Associate Professor Amanda Telford. Finally, we would like to thank the anonymous reviewers for their helpful feedback on previous iterations of this paper.

\section{Notes:}

${ }^{1}$ We acknowledge that at various times throughout this paper reification of female as femininity occurs, both through our engagement with the literature and in our participants' responses. It is important to point out that this representation manifests in the ways in which our participants present gender ideals, rather than as an indictment of the views of the researchers.

${ }^{2}$ Discursively football-netball clubs in rural and regional Australian contexts have been largely represented as gendered in that Australian Rules Football (AFL) is largely portrayed as a masculine sport and Netball as a predominantly feminine activity (as conveyed by the participants) but that both of these sports advocate opportunities for both male and female participation. In recent years there has been significant growth in the number of girls participating in AFL competition (both in girls only and mixed gender junior competitions and women’s football leagues). 


\section{References}

Atherley, K. 2006. "Sport, localism and social capital in rural Western Australia." Geographical Research 44 (4):348-60.

Atkinson, M., and Kehler, M. 2012. "Boys, Bullying and Biopedagogies in Physical Education." Thymos: Journal of Boyhood Studies 6 (2):166-85.

Australian Bureau of Statistics. 2008. Census of population and housing: Socio-Economic Indexes for Areas (SEIFA) - Technical paper, 2006 (Cat. No.2039.0.55.001). Canberra, Australia.

Australian Institute of Health and Welfare. 2004. Rural, regional and remote health: A guide to remoteness classifications (AIHW Cat. No. PHE 53). Canberra, Australia.

Azzarito, L. 2009. "The Panopticon of physical education: pretty, active and ideally white." Physical Education and Sport Pedagogy 14 (1):19-39.

Azzarito, L., and Solmon, M. 2006a. "A feminist poststructuralist view on student bodies in physical education: sites of compliance, resistance, and transformation." Journal of Teaching in Physical Education 25 (2):200-25.

— 2006b. "A poststructural analysis of high school students' gendered and racialized bodily meanings." Journal of Teaching in Physical Education 25 (1):75-98.

— 2009. "An investigation of students' embodied discourses in Physical Education: A gender project." Journal of Teaching in Physical Education 28 (2):173-91.

Bauer, K. K., Yang, Y. W., and Austin, S. B. 2004. "'How can we stay healthy when you're throwing all of this in front of us?" Findings from focus groups and interviews in middle schools on environmental influences on nutrition and physical activity." Health Education and Behavior $31(1): 34-46$. 
Butler, J. 1990. Gender trouble: Feminism and the subversion of identity. New York: Routledge.

—. 2004. Undoing gender. London: Routledge.

Cairns, K. 2014. "Both here and elsewhere: rural girls’ contradictory visions of the future." Gender and Education 26 (5):477-89.

Casey, M., Eime, R., Payne, W., and Harvey, J. 2009. "Using a socioecological approach to examine participation in sport and physical activity among rural adolescent girls." Qualitative Health Research 19 (7):881-93.

Casey, M., Mooney, A., Eime, R., Harvey, J., Smyth, J., Telford, A., and Payne, W. 2013. "Linking physical education with community sport and recreation: A program for adolescent girls." Health Promotion Practice 14 (5):721-31.

Cockburn, C., and Clarke, G. 2002. "'Everybody's looking at you!" Girls negotiating the 'femininity deficit' they incur in physical education." Women's Studies International Forum 25 (6):65165.

Coll, L., Enright, E., and O’Sullivan, M. 2014. "The Dangers of a Single Story: Heteronormativity in Physical Education. " In Sociocultural Issues in Physical Education: Case Studies for Teachers, edited by SB Flory, A Tischler and S Sanders. London: Rowman \& Littlefield.

Craike, M. J., Symons, C., Eime, R. M., Payne, W. R., and Harvey, J. T. 2011. "A comparative study of factors influencing participation in sport and physical activity for metropolitan and rural female adolescents." Annals of Leisure Research 14 (4):355-68.

Denison, E., and Kitchen, A. "Out on the fields: The first international study on homophobia in sport." RePUCOM. http://www.viewdocsonline.com/document/p0wnss.

Evans, J., Rich, E., Allwood, R., and Davies, B. 2008. "Body pedagogies, P/policy, health and gender." British Educational Research Journal 34 (3):387-402. 
Fitzpatrick, K. 2013. Critical pedagogy, physical education and urban schooling. New York: Peter Lang.

Flintoff, A., and Scraton, S. 2006. "Girls and physical education." In The handbook of physical education, edited by D. Macdonald, D. Kirk and M. O'Sullivan, 767-84. London: Sage Publications.

Foucault, M. 1977. Discipline and Punish: The birth of the prison. Translated by A. Sheridan. New York: Pantheon.

1980. Power/Knowledge: Selected interviews and other writings, 1972 - 1977. New York: Patheon.

. 1988. "The ethic of care for the self as a practice of freedom [Interview]." In The Final Foucault, edited by J. Bernauer and D. Rasmussen. Cambridge, MA: Massachusetts Institute of Technology Press.

Garrett, R. 2004. "Negotiating a physical identity: Girls, bodies and physical education." Sport, Education and Society 9 (2):223-37.

Gore, J. 1990. "Pegagogy as text in physical education teacher education: beyond the preferred reading." In Physical education, curriculum and culture: Critical issues in the contemporary crisis, edited by D Kirk and R Tinning, 79-108. London: Falmer Press.

1998. "Discplining bodies: On the continuity of power relations in pedagogy." In Foucault's challenge: Discourse, knowledge, and power in education, edited by TS. Popkewitz and M. Brennan, 231-51. New York: Teachers College Press.

Larsson, H., Redelius, K., and Fagrell, B. 2011. "Moving (in) the heterosexual matrix. On heteronormativity in secondary school physical education." Physical Education and Sport Pedagogy 16 (1):67-81. 
Law, J. 2004. After method: Mess in social science research. London: Routledge.

Lee, J., Macdonald, D., and Wright, J. 2009. "Young men's physical activity choices: The impact of capital, masculinities and location." Journal of Sport \& Social Issues 33 (1):59-77.

Mooney, A., and Casey, M. 2014. "'Girls get going’: Using Games Sense to promote physical activity amongst adolescent girls in rural and regional contexts in Australia." In Contemporary developments in games teaching, edited by R. Light, S. Harvey, J. Quay and A. Mooney. Milton Park, Abingdon: Routledge.

Mooney, A., Casey, M., and Smyth, J. 2012. "'You’re no-one if you’re not a netball girl”: Rural and regional living adolescent girls’ negotiation of physically active identities." Annals of Leisure Research 15 (1):19-37.

Paechter, C. 2003. "Power, Bodies and Identity: How different forms of physical education construct varying masculinities and femininities in secondary schools." Sex Education 3 (1):47-59.

Piro, J. M. 2008. "Foucault and the architecture of surveillance: Creating regimes of power in schools, shrines, and society." Educational studies 44 (1):30-46.

Roth, A., and Basow, S. A. 2004. "Femininity, Sports, and Feminism: Developing a Theory of Physical Liberation." Journal of Sport \& Social Issues 28 (3):245-65.

Singleton, E. 2006. " "We've got to stick to the curriculum, right?” An exploration of female high school physical educators "e beliefs about competition in their classes." Journal of Teaching and Learning 4 (1):15-30.

Slater, A., and Tiggemann, M. 2010. "'Uncool to do sport": A focus group study of adolescent girls' reasons for withdrawing from physical activity." Psychology of Sport and Exercise 11 (6):619-26. 
Slater, A., and Tiggemann, M. 2011. "Gender differences in adolescent sport participation, teasing, self-objectification and body image concerns." Journal of Adolescence 34 (3):455-63.

Smyth, J. 1998. Dialectical theory-building: juxtaposing theory with student voices in the noncompletion of schooling. Paper presented at the the annual meeting of the Australian Association for Research in Education, Adelaide.

Smyth, J., Mooney, A., and Casey, M. 2014. "Where has class gone to? The pervasiveness of class in girls' physical activity in a rural town." Sport, Education and Society 19 (1):1-18.

Spaaij, R. 2009. "The glue that holds the community together? Sport and sustainability in rural Australia." Sport in Society 12 (9):1132-46.

Tinning, R. 2010. "Pedagogy and human movement: Theory, practice, research." In International Studies in Physical Education and Youth Sport, edited by R Bailey. London: Routledge.

Webb, L., and Macdonald, D. 2007. "Techniques of power in physical education and the underrepresentation of women in leadership." Journal of Teaching in Physical Education 26 (3):279-97.

Webb, L., McCaughtry, N., and MacDonald, D. 2004. "Surveillance as a technique of power in physical education." Sport, Education and Society 9 (2):207-22.

Wright, J. 1995. "A feminist poststructuralist methodology for the study of gender construction in physical education: Description of a study." Journal of Teaching in Physical Education 15 (1):1-24.

. 1996. "Mapping the discourses of physical education: articulating a female tradition." Journal of Curriculum Studies 28 (3):331-51.

. 2000. "Discplining the body: Power, knowledge and subjectivity in a physical education lesson." In Culture and text: Discourse and methodology in social research and cultural 
studies, edited by A Lee and C. Poynton, 152-69. New South Wales, Australia: Allen \& Unwin.

2001. "Gender reform in physical education: a poststructuralist perspective." Journal of Physical Education New Zealand, 34 (1):15-25.

. 2009. "Biopower, biopedagogies and the obesity epidemic." In Biopolitics and the 'obesity epidemic, edited by Jan Wright and Valerie Harwood, 1-14. New York: Routledge.

Wright, J., and Burrows, L. 2006. "Re-conceiving ability in physical education: a social analysis." Sport, Education \& Society 11 (3):275-91. 